\title{
Influence of Sodium Lignosulfonate on the Corrosion-Inhibition Behavior of Q235 Steel in Simulated Concrete Pore Solutions
}

\author{
Jiansan Li, Weilin Liu*, Wanchen Xie \\ School of Mechanical and Automotive Engineering, South China University of Technology, \\ Guangzhou 510640, People's Republic of China \\ *E-mail: 201821003510@mail.scut.edu.cn
}

doi: $10.20964 / 2020.08 .02$

Received: 31 March 2020 / Accepted: 11 May 2020 / Published: 10 July 2020

\begin{abstract}
The corrosion mechanism and behavior of Q235 steel treated with sodium lignosulfonate and a mixture of sodium lignosulfonate and sodium silicate inhibitors in simulated concrete pore (SCP) solutions containing $0.08-\mathrm{mol} / \mathrm{L} \mathrm{NaCl}$ were evaluated using polarization methods, electrochemical impedance spectroscopy, scanning electron microscopy, weight-loss measurements, and potential-of-zero-charge analysis. Results verified that the inhibition efficiency rapidly increased as the sodium lignosulfonate content increases, and the adsorption process mainly comprised chemisorption. The optimum sodium lignosulfonate concentration was $0.0015 \mathrm{~mol} / \mathrm{L}$. Sodium lignosulfonate and sodium silicate showed a synergistic inhibition effect in SCP solutions, with the highest inhibition efficiency of $98.8 \%$ achieved when $0.0005-\mathrm{mol} / \mathrm{L}$ sodium lignosulfonate and $0.0005-\mathrm{mol} / \mathrm{L}$ sodium silicate were used.
\end{abstract}

Keywords: sodium lignosulfonate; sodium silicate; Q235 steel; corrosion inhibition; simulated concrete pore solution

\section{$\underline{\text { FULL TEXT }}$}

(C) 2020 The Authors. Published by ESG (www.electrochemsci.org). This article is an open access article distributed under the terms and conditions of the Creative Commons Attribution license (http://creativecommons.org/licenses/by/4.0/). 